\title{
Extraction of Novel Galactoarabinan-Rich Pectin with Gelling Capacity from Soursop Pomace
}

\section{Besson', Beda M Yapo ${ }^{2,3 *}$ and Kouassi L Koffi ${ }^{1,4}$}

${ }^{1}$ Food Research and Technology Division, Cargill West Africa, Abidjan, Côte d'Ivoire

'Unit of Training and Research in Food Science and Technology, University of Nangui-Abrogoua of Abobo-Adjamé, 02 BP 801 Abidjan, Côte d'Ivoire

${ }^{3}$ Unit of Training and Research in Agroforestry, Subunit of Pedagogy in Biochemistry and Microbiology, University of Jean Lourougon Guédé, BP 150 Daloa, Côte d'Ivoire

${ }^{4}$ Polytechnique National Institute of Felix Houphouet Boigny, BP V79 Abidjan, Cote d'Ivoire

\begin{abstract}
The effect of the strength of nitric acid-extractant $(\mathrm{pH} \mathrm{1.2,1.6,} \mathrm{and} \mathrm{2.0)} \mathrm{on} \mathrm{the} \mathrm{yield,} \mathrm{sugar} \mathrm{composition} \mathrm{and}$ molecular weight, and gelling ability of pectin from soursop (Annona muricata) was investigated to find out the optimum conditions for producing marketable pectin. The results showed that the yield (3.5-12.9\%) of pectin (AMP) extracted from Annona muricata pomace was $\mathrm{pH}-$ dependent. Likewise, its galacturonic acid content (GalA: 41.3-72.8\%), total neutral sugar content (TNS: 11.4-24.3\%), methylesterification degree (DM: 64-82), viscosity-average-molecular weight (Mv: 62-105), and gelling capacity (GC: 98-163) were significantly influenced by the extraction $\mathrm{pH}(\mathrm{p}<0.05)$. Individual neutral sugar analysis revealed that arabinose was the most abundant, followed by galactose with a rather high presence of rhamnose. Partial structural analysis, by enzymatic degradations, suggested that AMP was mainly branched with an unusual galactoarabinan side chain type rather than with arabinogalactan-I. As the other extraction parameters, namely dried raw material to solvent ratio, temperature, and time, were fixed to $1: 25(\mathrm{w} / \mathrm{v}), 75^{\circ} \mathrm{C}$, and 90 min, respectively; $\mathrm{pH} 1.2$ was found to be the optimum $\mathrm{pH}$ condition for isolating, from soursop pomace, high methoxy pectin $(\mathrm{DM}>60 \%)$ with rather good yield $(8.0 \%)$ and gelling power $(>150)$.
\end{abstract}

Keywords: Annona muricata; Pomace; Pectin; Galactoarabinan; Gelatio

\section{Introduction}

TCell walls of higher plants are composed of three kinds of polysaccharides, namely, cellulose, non cellulosic cross-linking heteroglycans (ex. hemicelluloses) and pectic substances. The latter polymers are highly diversified that they are believed to form a family of at least eight polysaccharides, two of which (homogalacturonan and rhamnogalacturonan-I) are commonly found in all (if not most) of the plant cell walls so far investigated. Homogalacturonan $(\mathrm{HG})$ is an unbranched $1,4-\alpha-\mathrm{D}-\mathrm{Gal} p \mathrm{~A}$ polymer methyl-esterified at $\mathrm{C}-6$ position and sometimes acetyl-esterified at $\mathrm{O}-2$ and/or $\mathrm{O}-3$ positions. Rhamnogalacturonan-I (RG-I) is a [1,4]- $-\mathrm{D}-\mathrm{D}-\mathrm{Gal} p \mathrm{~A}-1,2-\alpha-$ L-Rhap-[1,4] polymer branched with different types of neutral sugar side chains. Common branches of RG-I consist of 1,5- $\alpha$-L-arabinan, $1,4-\beta-D$-galactan, and arabinogalactan-I (AG-I). They may, however, be ramified with more complex polysaccharide moieties, such as arabinogalactan-II (AG-II), commonly found in arabinogalactanprotein (AGP) and unusual galactoarabinan (GA) [1]. No less than 17 monosaccharides have been detected in pectic polysaccharides [2]. However, typical acid (AS) and neutral (NS) sugar constituents of the pectin HG and RG-I block copolymers are of four sorts, viz., $\alpha$-D-galactopyranosyluronic acid ( $\alpha-\mathrm{D}-\mathrm{Gal} p \mathrm{~A}), \alpha$-L-rhamnopyranose $(\alpha-\mathrm{L}-\mathrm{Rha} p), \alpha-\mathrm{L}$-arabinofuranose ( $\alpha$-L-Araf), and $\beta$ D-galactopyranose $(\beta-\mathrm{D}-\mathrm{Gal} p)$. As conveyed by the name per se, "pectin" [in reference to the Greek word 'pektikos', which means to "congeal, solidify or curdle" [3] is a naturally gelling polysaccharide mainly exploited for this functionality in the art of manufacturing various gelling products such as marmalades, jams, preserves, and low calorie jellies and confections.

To date, commercial pectins are produced from two pectin-rich sources (citrus peels and apple pomace) under specified extraction conditions kept secret by producers, but thought to be generally confined to the following: dry raw material to solvent weight ratio 1:351:15 (w/v), water acidified with $\mathrm{HNO}_{3}$ (or $\mathrm{HCl}$ ) to $\mathrm{pH} \mathrm{1-3,} \mathrm{temperature}$ $60-100^{\circ} \mathrm{C}$, and time $30-180 \mathrm{~min}[4-6]$. Diverse studies have shown that the yield, sugar composition (especially GalA content), esterification degree, and functional (gelling) properties of pectins are influenced by the conditions used for extraction $[7,8]$ and therefore optimization is required for every new pectin source, which is being investigated for marketing purposes.

Furthermore, industrial pectins are hitherto mainly produced in Europe and the United States of America. Thus, pectin import in developing countries such as Côte d'Ivoire and neighboring countries to satisfy the interior and regional demands represents an expensive enterprise with a low added value to domestically manufactured gelling products and confectioneries. As a consequence, importation of readyto-eat preserves and confectioneries are prioritized at the expense of some home-made gelling products by food firms, thereby resulting in bankrupt of small- and medium-size local gelling food plants and jobless increase.

To partially remedy to this "abnormal situation", various unutilized agricultural byproducts, available in large quantities, are selectively screened for possible production of marketable pectins. This paper presents the results of our investigation on the yield, quality characteristics, and gelling ability of pectins extracted from soursop pomace. The pomace is a byproduct of medium-size juice plants. Daily drink of soursop fruit juice (as well as its leaves infusion) is gaining more and more attraction in Ivorian society, because these beverages are thought to possess some "miracle health-benefit effects" such as anti-insomnia, anti-stressing, anti-depressant, anti-microbial and even anti-tumor properties.

*Corresponding author: Beda M Yapo, Unit of Training and Research in Food Science and Technology, University of Nangui-Abrogoua of Abobo-Adjamé, 02 BP 801 Abidjan, Côte d'Ivoire, Tel: +225 487361 30/32 7810 88; Fax: +225 327875 70; E-mail: bedamarcel@yahoo.fr

Received August 10, 2013; Accepted September 27, 2013; Published October 05, 2013

Citation: Besson V, Yapo BM, Koffi KL (2013) Extraction of Novel GalactoarabinanRich Pectin with Gelling Capacity from Soursop Pomace. Nat Prod Chem Res 1 : 117 doi:10.4172/ 2329-6836.1000117

Copyright: $\odot 2013$ Besson V, et al. This is an open-access article distributed under the terms of the Creative Commons Attribution License, which permits unrestricted use, distribution, and reproduction in any medium, provided the original author and source are credited. 


\section{Material and Methods}

\section{Alcohol insoluble material (AIM) preparation}

Dried pomace of soursop was a gift from a medium-size factory of domestic juice producer (ATOU, Abidjan, Côte d'Ivoire). Alcohol insoluble material (AIM) was prepared from the raw material, by heating pomace in boiling $80 \%(\mathrm{v} / \mathrm{v})$ ethanol for $25 \mathrm{~min}$ and washing the residue with $70 \%(\mathrm{v} / \mathrm{v})$ ethanol, to remove free sugars, pigments and other impurities until the filtrate gave a negative response with the phenol-sulfuric acid test [9]. The residue was then dried by solvent exchange ( $95 \%$ ethanol and absolute acetone), placed in a fume hood for $5 \mathrm{~h}$ for residual acetone evaporation and oven-dried overnight. Dried AIM was ground in a hammer mill (Model 912, Winona Attrition Mill Co.,Winona, MN) to pass through a $12 \mathrm{~mm}$ size sieve and was kept under moisture-free conditions until use.

\section{Pectin extraction}

Prior to extracting pectins by water acidified with $1 \mathrm{~N} \mathrm{HNO}_{3}$ to different $\mathrm{pH}(1.2,1.6$, and 2.0), AIM was successively treated with heat stable aamylase (Termamyl, Novozymes, Bagsvaerd, Denmark), protease (Sigma Chemical Co., St. Louis, MO), and amyloglucosidase (Sigma Chemical Co., St. Louis, MO) as previously described [10]. On the basis of our previous work on various pectin sources [6,8], pectins were extracted from destarched and deproteinated AIM (DDAIM) using a relatively simple experimental design for optimization. Only the $\mathrm{pH}$ of solvent was varied from 1.2 to 2.0 per 0.4 unit intervals (1.2, 1.6, and 2.0), the other extraction parameters, namely solid to liquid extractant $(\mathrm{S} / \mathrm{L})$ ratio, temperature $\left(\mathrm{T}^{\circ} \mathrm{C}\right)$, and time $(\mathrm{t})$, being fixed to 1:25 (w/v), $75^{\circ} \mathrm{C}$ and $90 \mathrm{~min}$, respectively. Two successive extractions were carried out before discarding any remaining insoluble cell wall fraction. At the end of every extraction, slurry was clarified and pectin extract was rapidly brought to $\mathrm{pH} 4$ for stability. The first and second extracts were combined, concentrated, and precipitated in 3 volumes of $95 \%$ ethanol at $5^{\circ} \mathrm{C}$ for $2 \mathrm{~h}$. Pectin precipitates were washed two-times with $70 \%$ ethanol, followed by $95 \%$ ethanol and acetone, and kept for a while under a fume extractor (for residual acetone evaporation), and finally oven-dried at $45^{\circ} \mathrm{C}$ overnight and weighed. Extraction of pectins was performed in three independent runs for each selected $\mathrm{pH}$ value. Dried pectin flakes were finely ground to powders passing through 60mesh $(\# 0.25 \mathrm{~mm})$ size sifters, canned in plastic containers and store at room temperature under airless and moisture-free conditions until use.

\section{Pectin characterization}

Pectin samples were first treated with a mixture of $1 \%(\mathrm{v} / \mathrm{v})$ $\mathrm{HCl} / 60 \%$ (v/v) ethanol (three times), and insolubles were exhaustively washed with $60 \%(\mathrm{v} / \mathrm{v})$ ethanol until the filtrate gave a negative response for chloride ions with silver nitrate. This treatment aimed at removing free sugars and salts and converting all the carboxyl groups of pectin macromolecules to the free acid (-COOH) form for titration with 1 $\mathrm{N} \mathrm{NaOH}$ solution. Pectins were characterized for the glycosyl residue and linkage compositions, esterification degree, molecular weight, and gelling capacity.

Analytical: To quantify monosaccharide constituents, DDAIM was first hydrolyzed with 1 mol. $\mathrm{L}^{-1} \mathrm{H}_{2} \mathrm{SO}_{4}\left(100^{\circ} \mathrm{C}, 3 \mathrm{~h}\right)$ after pretreatment with 12 mol.L $\mathrm{L}^{-1} \mathrm{H}_{2} \mathrm{SO}_{4}\left(23^{\circ} \mathrm{C}, 1 \mathrm{~h}\right)$ and purified pectins were directly hydrolyzed with $1 \mathrm{~mol} \cdot \mathrm{L}^{-1} \mathrm{H}_{2} \mathrm{SO}_{4}\left(100^{\circ} \mathrm{C}, 3 \mathrm{~h}\right)$ as previously reported [10]. The GalA content of DDAIM and purified pectins was colorimetrically quantified at $525 \mathrm{~nm}$ by a modified sulfamate-meta-hydroxydiphenyl (MHDP) assay using monoGalA standard [11]. Liberated neutral sugars (NS) from purified pectins, especially galactose/arabinose (Megazyme procedure) and rhamnose [12] were quantified spectrophotometrically at $340 \mathrm{~nm}$ using Megazyme assay kits (Megazyme International Ireland Ldt., Bray, Co. Wicklow, Ireland). The NS assays were based on the quantitative oxidation of galactose/arabinose and rhamnose to corresponding lactonic derivatives (D-galactono-(1,4)-lactone for $\alpha$-L-Arabinose and $\beta$-D-Galactose and L-rhamno-(1,4)-lactone for $\alpha$-L-rhamnose) in the presence of corresponding deshydrogenases $[\beta$-galactose dehydrogenase $(\beta-\mathrm{GalDH})$ plus galactose mutarotase (GalM) for $\alpha$-L-arabinose and $\beta$-D-galactose, and L-rhamnose deshydrogenase (RhaDH) for $\alpha$-L-rhamnose] and the coenzyme $\mathrm{NAD}^{+}$, which is stoichiometrically reduced to NADH with maximum absorbance at $340 \mathrm{~nm}$. D-galactose was quantitatively differentiated from $\mathrm{L}$-arabinose by reading absorbance at different reaction times, namely after $6 \mathrm{~min}$ - and $12 \mathrm{~min}$-reaction at room temperature, respectively. L-rhamnose was quantitatively determined after $1 \mathrm{~h}$ reaction at room temperature. Total neutral sugar (TNS) was calculated as the sum of individual amounts of NS (Ara, Gal, and Rha) determined. Alternatively, TNS was estimated by the tri-reagent (anthrone, orcinol, and MHDP) colorimetric- $\mathrm{H}_{2} \mathrm{SO}_{4}$ assay as reported previously [13]. The glycosyl linkage was determined by methylation analysis as previously reported [6].

The molar ratio of HG to RG-I block copolymers was roughly estimated using relation $1[1,14]$.

HG/RG-I=100×[GalA(\%)-Rha(\%)]/[2 Rha(\%)+Ara(\%)+Gal(\%)] (1)

The degree of branching (DBr) of pectins rhamnosyl residues with NS side chains was roughly estimated, by equation 2 , as previously reported [15].

$$
\mathrm{DBr}=\mathrm{Rha}(\%) /[\mathrm{Ara}(\%)+\mathrm{Gal}(\%)]
$$

The types of NS side chains branching the RG-I block copolymer were discriminated by treating pectin samples with highly purified $\alpha$-L-arabinanase $(+\alpha$-L-arabinosidase and/or $\beta$-D-galactanase $(+\beta-D$ galactosidase). Each of the enzymatic preparations had no measurable activity other than the activity which it was specified for. The overall esterification degree (DE) of pectic samples was potentiometrically determined as previously described [13]. The acetylesterification degree (DAc) was colorimetrically measured at $510 \mathrm{~nm}$ by the hydroxamic acid assay using glucose pentaacetate standard [16] and the methylesterification degree (DM) was differentially evaluated. All the measurements were performed in triplicates.

Macromolecular analysis: The molecular weight of pectin samples was analysed by GFC on a high resolution Superdex-200 HR 10/30 column (Amersham Biosciences Corp., NJ). A molecular weight kit of pullulan standards $(M w \sim 6.0,10.0,21.7,48.8,113.0,210.0,393.0$, and $805.0 \mathrm{kDa} ; M w / M n \sim 1.0-1.2)$ from American Polymer Standards Corp. (Mentor, $\mathrm{OH}$ ) and purified homogenous HG standards ( $\mathrm{Mw} \sim 60$ and $100 \mathrm{kDa}, M w / M n \sim 1.0-1.2$ ) [6], with known intrinsic viscosity [ $\eta$ ] and $M w$ values, were used for calibration. To better estimate the the Mv of pectins, the so-called universal calibration technique (UCT) was used by plotting $\log \left([\eta] \times M_{w}\right)$ versus the elution volume $\left(\mathrm{V}_{\mathrm{e}}\right)$ of standards. Analyses were performed in triplicates.

\section{Gelling properties}

The gelling capacity (or power) of pectins was evaluated by the determination of the strength of gels prepared under the following conditions: $65.0 \%$ soluble solids (sucrose), $0.70 \mathrm{wt} \%$ pectin, and at $\mathrm{pH}$ 2.3 as previously described [6].

\section{Statistical analysis}

The data were statistically evaluated by the global test of a single- 
factor analysis of variance (ANOVA), followed by the Bonferroni's posthoc test for multiple comparisons, whenever applicable, using a GraphPad Prism V.3 software (GraphPad software Inc., San Diego, CA). Means of different treatments were considered significantly different at $p<0.05$.

\section{Results and Discussion}

\section{Extraction yield of Annona muricata pectins (AMP)}

The "pectin content" of DDAIM, which accounted for about $70.2 \pm$ $3.1 \%$ (three measurements) of the dried raw material (DRM), was 24.5 $\pm 1.3 \%$ on a GalA basis. Thus, the pectin content of DRM was estimated at approximately $17.2 \pm 1.9 \%$. This showed that dried soursop pomace was a pectin-rich source, which deserved to be explored for possible mass production of marketable pectin. The yields of extracted Annona muricata pectins (AMP) are shown in Table 1. The yields of $\mathrm{pH} 1.2-$ AMP, $\mathrm{pH}$ 1.6-AMP, and $\mathrm{pH}$ 2.0-AMP isolates were 8.2, 12.9, and 3.5\%, respectively. These pectin yields were significantly different from one another $(p<0.05)$, showing that the pectin yield was greatly influenced by the extraction $\mathrm{pH}$. It appeared that increasing the acid-extractant strength resulted in increase of the pectin yield. However, the fact that the yield significantly decreased from 12.9 to $8.2 \%$, as the strength of extractant was increased from $\mathrm{pH} 1.6$ to $\mathrm{pH} \mathrm{1.2,} \mathrm{indicated} \mathrm{that}$ solubilized pectin macromolecules were rather substantially degraded in the HG and/or RG-I (block copolymer) domains.

\section{Chemical features of extracted pectins}

Sugar composition and block copolymers: The sugar composition of extracted pectins is shown in Table 1. The galacturonic acid (GalA) content of pectins ranged from $41.3-72.8 \%$ as the extraction $\mathrm{pH}$ was varied from $\mathrm{pH} 1.2$ to $\mathrm{pH}$ 2.0. The amounts of GalA in extracted pectins were significantly different from one another $(p<0.05)$, showing that this important constituent of pectin was affected by the extraction $\mathrm{pH}$. The $\mathrm{pH}$ 1.2-AMP isolate had the highest GalA content, which was $>65 \%$, one of the required quality characteristics for possible mass production. However, as can be seen above, the yield of $\mathrm{pH}$ 1.2-AMP isolate was lower than the yield of $\mathrm{pH}$ 1.6-AMP isolate, suggesting that more extensive degradation of solubilized pectin polymers at $\mathrm{pH} 1.2$ might mainly occurred in the NS-containing RG-I regions rather than in the HG regions. The three typical NS of pectic substances, namely rhamnose, arabinose, and galactose were detected in all the purified samples, but in different relative amounts from one sample to another. Arabinose (5.4-13.2\%) was the major NS, followed by galactose (3.8$6.5 \%)$ and rhamnose (2.2-4.6\%). These results suggested that acidextracted pectins from soursop pomace were profusely branched, in their RG-I domains, with arabinose-containing side chains. This observation is in accord with the hypothesis that cold water-insoluble pectin, contained in AIM of corossol pulp, might be less linear than cold-water soluble pectin from the same AIM, due to high recurrence of rhamnose in the backbone bearing mainly arabinose-containing side chains [17].

To discriminate the types of NS-side chains RG-I polymers were branched with, highly purified arabinan- and galactan-degrading enzymatic preparations were used to treat the AMP isolate which had the highest NS content, notably the isolate obtained at $\mathrm{pH}$ 1.6. It was observed that $\alpha$-L-arabinanase was very active, removing more $80 \%$ of the arabinose initially present, whereas $\alpha$-L-arabinosidase was inhibited by this pectin isolate. However, the mixture [ $\alpha$-L-arabinanase $+\alpha-$ $\mathrm{L}$-arabinosidase] resulted in more than $95 \%$ removal of arabinose residue and the mixture [ $\alpha$ - $\mathrm{L}$-arabinosidase $+\beta \mathrm{D}$-galactosidase] led to about $10 \%$ removal of arabinosyl residues. These results, taken together, strongly suggested that the bulk of arabinosyl residues were not in chain-terminating position, but in relatively long (and scarcely ramified) arabinans. Furthermore, $\beta$-D-galactanase was found to be inactive against the pectin isolate, whereas $\beta$-D-galactosidase was considerably active, removing no less than $98 \%$ of the galactose initially present with the sample. This indicated that most galactosyl residues were in chain-terminating position. On the other hand, glycosyl linkage analysis substantiated that most arabinosyl residues were 1,5-linked Ara residues with some 1,3-linked Ara residues, and galactosyl residues were chiefly terminal Gal residues with some 1,4-linked Gal residues (results not shown). In the light of all these data, we believed that the RG-I regions of AMP were primarily branched with unusual type of NS polymers, namely galactoarabinans (GA), rather than by type one arabinogalactans (AG-I), commonly found in pectins. Pectic fractions from some other plant materials, notably sugar beet pulp, potato tubers, and blackgram native and fermented products have also been reported to be branched with GA $[1,18-20]$.

The TNS contents of $\mathrm{pH}$ 1.2-AMP, $\mathrm{pH}$ 1.6-AMP, and $\mathrm{pH}$ 2.0-AMP isolates, determined by calculating the sum of rhamnose, arabinose, and galactose were $11.4,24.3$, and $15.7 \%$, respectively (Table 1). These values were similar to those $(12.2,25.1 ; 20.4 \%$, respectively) measured by the tri-reagent method, except for the $\mathrm{pH}$ 2.0-AMP isolate where underestimation occurred with the former method. Hence, the monosaccharides contained in all the AMP isolates, but the $\mathrm{pH}$ 2.0-isolate, were all from pectic macromolecules, thereby indicating that the other two were highly purified pectin samples. This discrepancy could be ascribed to contaminating glucose-containing oligosaccharides from residual degraded starchy polysaccharides present in DDAIM. Corossol fruit pulp, like apple fruit pulp, has indeed been reported to be rich in starchy polysaccharides [17].

The amounts of TNS in all the AMP isolates were significantly different from one another $(p<0.05)$. The TNS content of the $\mathrm{pH}$ 1.2-isolate was the lowest, probably due to more substantial degradation of GA-branched RG-I regions. This was likely supported by the observation that this pectin isolate had much lower Rha to GalA molar ratio (3.6\%), compared with the other two samples (7.89.2\%). In contrast, the degree of branching (DBr: 20.0-23.2\%) was not significantly affected, suggesting that arabinose, galactose, and rhamnose might be degraded at similar rates in the course of pectin polymers solubilisation in acid-extractant from soursop pomace.

The relatively high sensitivity and lability of those neutral sugars, especially arabinofuranosyl residues to acid are well demonstrated in the literature $[7,8,21]$. The amount of HG was above $50 \%(62.8$ $80.9 \%$ ), indicating that this block copolymer was dominant over RG-I with the pectin structure assuming that isolates contained no free pectic stretches. The $\mathrm{pH}$ 1.2-AMP isolate consisted of more HG block copolymers than the remainder, which was reflected in the HG to RG-I ratio, ranging from 1.5 to 4.2 (Table 1). The values of the HG/RG-I ratio suggested that 2 to $4 \mathrm{HG}$ per RG-I block copolymers might be present within AMP isolates.

\section{Degree of esterification}

The degree of methylesterification (DM) of extracted pectins ranged from 64-82 (Table 1), indicating that soursop cell wall pectins are highly methylesterified. The highest value of DM was obtained at $\mathrm{pH} 2.0$ and the lowest at $\mathrm{pH} 1.2$, probably due to degradation of pectin ester-groups under more severe extraction conditions. The degree of acetylesterification (DAc) was relatively low $(\leq 10 \%)$. On the basis the results obtained, the extraction conditions of $\mathrm{S} / \mathrm{L}(1: 25 \mathrm{w} / \mathrm{v}), \mathrm{T}\left(75^{\circ} \mathrm{C}\right)$, $\mathrm{t}(90 \mathrm{~min})$, and $\mathrm{pH} 1.2$ appeared to be the optimum conditions for the 
isolation of pectin with high GalA content $(>65 \%)$ and DM $(>60 \%)$, from soursop pomace, two of the quality characteristics that needed to be fulfilled for possible mass production and marketing.

\section{Macromolecular features}

The intrinsic viscosity $([\eta])$ and molecular weight of AMP ranged from $307-408 \mathrm{~mL} / \mathrm{g}$ and from $62-105 \mathrm{kDa}$, respectively (Table 1 ). The intrinsic viscosity of $\mathrm{pH}$ 1.6-AMP isolate was the smallest, followed by the intrinsic viscosity of $\mathrm{pH}$ 2.0-AMP isolate and finally by that of $\mathrm{pH}$ 1.2-AMP isolate. By contrast, the molecular weight of $\mathrm{pH}$ 1.6AMP isolate was the highest, followed by the molecular weight of $\mathrm{pH}$ 1.2-AMP isolate and finally by the molecular weight of $\mathrm{pH}$ 2.0-isolate. These results suggested that the former pectin very likely had an overall compact sphere-like conformation, while the latter may have a rather extended rod-like conformation. This somewhat inverse relationship which was observed between the pectin $M v$ and [ $\eta$ ] could be explained by higher degree of branching $(\mathrm{DBr})$ of $\mathrm{pH}$ 1.6-AMP isolate with amply flexible GA side chains, thereby fostering a roll-up of the macromolecule over on itself, a result of which was an overall sphere-like compact macrostructure with a shorter hydrodynamic size $[1,10,22]$.

\section{Gelling capacity}

The strength of AMP gels ranged from 98-163 (Table 1). The $\mathrm{pH}$ 1.2-AMP isolate had a much greater gelling ability $(>150)$, one of the international quality characteristics required for possible marketing. This could be accounted for by high GalA content (>65\%), DM (>60\%), and $M v(>80 \mathrm{kDa})$, three parameters known to substantially influence sugar-acid-mediated gelation of pectin [5,6]. The gelling ability of $\mathrm{pH}$ 2.0-AMP was considerably low, and therefore this sample may be more suitable for the preparation of calcium-mediated gels rather than for sugar-acid-mediated gels. This rather weak gelling power might be caused by the relatively low GalA content and $M v$, but probably also by the presence in this sample of contaminating starchy oligosaccharides, which acted as destabilizing agent of pectin gel networks [6].

The gelling capacity of pectin from a plant source is (one of) the most determining factors for possible industrial production. Our results showed that pectin with rather good yield, quality characteristics

\begin{tabular}{|c|c|c|c|}
\hline & \multicolumn{3}{|c|}{ AMP } \\
\hline & pH 1.2 & pH 1.6 & $\mathrm{pH} 2.0$ \\
\hline Yield (\% DRM) & $8.2 \pm 1.4 a$ & $12.9 \pm 1.8 b$ & $3.5 \pm 1.1 \mathrm{c}$ \\
\hline $\begin{array}{l}\text { GalA (\% w/w) } \\
\text { Rha (\% w/w) }\end{array}$ & $\begin{array}{c}72.8 \pm 3.1 a \\
2.2 \pm 0.5 a\end{array}$ & $\begin{array}{c}59.6 \pm 2.4 b \\
4.6 \pm 0.8 b\end{array}$ & $\begin{array}{c}41.3 \pm 1.7 \mathrm{c} \\
2.7 \pm 0.9 a\end{array}$ \\
\hline $\begin{array}{l}\text { Ara }(\% \mathrm{w} / \mathrm{w}) \\
\text { Gal }(\% \mathrm{w} / \mathrm{w})\end{array}$ & $\begin{array}{l}5.4 \pm 0.6 a \\
3.8 \pm 1.4 a\end{array}$ & $\begin{array}{c}13.2 \pm 1.9 a \\
6.5 \pm 1.7 a\end{array}$ & $\begin{array}{l}8.1 \pm 1.7 \mathrm{c} \\
4.9 \pm 1.3 a\end{array}$ \\
\hline $\begin{array}{l}\text { TNS (\% w/w) } \\
\text { Rha/GalA }\end{array}$ & $\begin{array}{c}11.4 \pm 0.9 a \\
3.6: 100 a\end{array}$ & $\begin{array}{c}24.3 \pm 2.1 b \\
9.2: 100 b\end{array}$ & $\begin{array}{c}15.7 \pm 1.4 \mathrm{c} \\
7.8: 100 \mathrm{~b}\end{array}$ \\
\hline $\begin{array}{l}\mathrm{DBr}(\%) \\
\mathrm{HG}(\mathrm{mol} \%)\end{array}$ & $\begin{array}{c}23.2 \pm 1.9 \\
80.9 \pm 2.6 a\end{array}$ & $\begin{array}{c}22.3 \pm 2.1 \\
60.3 \pm 2.9 a b\end{array}$ & $\begin{array}{r}20.0 \pm 1.3 \\
62.8 \pm 2.3 \mathrm{~b}\end{array}$ \\
\hline $\begin{array}{l}\text { RG-I (mol\%) } \\
\text { HG/RG-I (\%) }\end{array}$ & $\begin{array}{c}19.1 \pm 1.8 a \\
4.2 \pm 0.9 a\end{array}$ & $\begin{array}{c}39.7 \pm 2.2 b \\
1.5 \pm 0.1 b\end{array}$ & $\begin{array}{c}37.2 \pm 1.7 b \\
1.7 \pm 0.2 b\end{array}$ \\
\hline DM & $64 \pm 4 a$ & $73 \pm 8 b$ & $82 \pm 3 c$ \\
\hline DAc & $5 \pm 1$ & $6 \pm 3$ & $10 \pm 4$ \\
\hline$[\eta](\mathrm{mL} / \mathrm{g})$ & $408 \pm 3 a$ & $307 \pm 6 b$ & $364 \pm 5 c$ \\
\hline $\begin{array}{l}\text { Mv (kDa) } \\
\text { Gel strength ( }{ }^{\circ} \text { sag) }\end{array}$ & $\begin{array}{c}84 \pm 8 a \\
163 \pm 3 a\end{array}$ & $\begin{array}{c}105 \pm 10 b \\
145 \pm 2 b\end{array}$ & $\begin{array}{l}62 \pm 3 c \\
98 \pm 4 c\end{array}$ \\
\hline
\end{tabular}

Data are expressed as mean $\pm \operatorname{SD}(n=3)$. Mean values in the same line with different

letters are significantly different $(p<0.05)$.

AMP: Annona muricata pectin

DRM: Dried raw material

Table 1: Glycosyl residue composition, macromolecular features, and gelling capacity of acid-extracted pectin from Annona muricata pomace. and gelling capacity could be extracted from soursop pomace under specified conditions.

\section{Conclusion}

Investigation on the pectin content of soursop pomace showed that this domestically available byproduct is a pectin-rich source. Soursop pomace contains approximately $17 \%$ pectic substances. Under optimized extraction conditions about $8 \%$ pectin, which fulfills required quality characteristics (galacturonic acid amount $>65 \%$, degree of methoxylation $>60 \%$, average-molecular weight $>70-80$ $\mathrm{kDa}$ and gelling ability $>150$ ) for possible mass production, has been purified from this raw material. Soursop pomace then appeared to be a potentially new source of industrial pectin able to partially substitute for benchmark citrus and apple pectins.

\section{Acknowledgement}

We are grateful to Cosmivoire and Cargill West Africa for some financial support.

\section{References}

1. Yapo BM (2011) Rhamnogalacturonan-l: A structurally puzzling and functionally versatile polysaccharide from plant cell walls and mucilages. Polymer Reviews 51: $391-413$

2. Vincken JP, Schols HA, Oomen RJFJ, McCann MC, Ulvskov P (2003) If homogalacturonan were a side chain of rhamnogalaturonan I. Implications for cell wall architecture. Plant Physiology. 132: 1781-1789.

3. Braconnot $\mathrm{H}$ (1825) Recherches sur un nouvel acide universellement répandu dans tous les végétaux. Annales de Chimie et de Physique 28: 173-178.

4. May CD (1990) Industrial pectins: sources, production and applications. Carbohydrate Polymers. 12; 79-99.

5. Voragen AGJ, Pilnik W, Thibault JF, Axelos MAV, Renard CMGC (1995) Pectins. In: Stephen, A.M., Ed., Food polysaccharides and their applications, Marcel Dekker., New York, 287-339.

6. Yapo BM (2009) Pineapple and banana pectins comprise fewe homogalacturonan building blocks with a smaller degree of polymerization as compared with yellow passion fruit and lemon pectins: Implication for gelling properties. Biomacromolecules 10: 717-721

7. Canteri-Schemin MH, Fertonani HCR, Waszczynskyj N, Wosiacki G (2005) Extraction of pectin from apple pomace. Brazilian Archives of Bioliology and Technology. 48: 259-266.

8. Yapo BM, Robert C, Etienne I, Wathelet B, Paquot M (2007) Effect of extraction conditions on the yield, purity and surface properties of sugar beet pulp pectin extracts. Food Chem 100: 1356-1364.

9. Dubois M, Gilles KA, Hamilton JK, Rebers PA, Smith F (2006) Colorimetric method for determination of sugars and related substances. Analytical Chem 28: $350-356$

10. Yapo BM, Koffi KL (2008) Dietary fiber components in yellow passion fruit rinds-A Potential Fiber Source. Journal of Agricultural and Food Chem 56: 5880-5883.

11. Yapo BM (2010) Improvement of the compositional quality of monocot pectin extracts contaminated with glucuronic acid-containing components using a step-wise purification procedure. Food and Bioproducts Processing 88: 283290.

12. Turecek PL, Buxbaum E, Pittner F (1989) Quantitative determination of pectic substances as an example of a rhamnopolysaccharide assay. Journal of Biochemical and Biophysical Methods 19: 215-222.

13. Yapo BM, Koffi KL (2013) Utilisation of model pectins reveals the effect of demethylated block size frequency on calcium gel formation. Carbohydrate Polymers 92: 1-10

14. M šsakni NH, Majdoub H, Roudesli S, Picton L, Le Cerf D, et al. (2006) Composition, structure and solution properties of polysaccharides extracted from leaves of Mesembryanthenum crystallinum. Eur Polymer J 42: 786-795.

15. Yapo BM, Koffi, KL (2006) Yellow passion fruit rind-a potential source of lowmethoxyl pectin. J Agric Food Chem 54: 2738-2744. 
16. McComb EA, McCready RM (1957) Determination of acetyl in pectin and in acetylated carbohydrate polymers. Anal Chem 29: 819-821.

17. Vaillant F, Millan C, Tchiliguirian C, Reynes M (1998) Preliminary characterization of the cell wall polysaccharides of the corossol pulp and study of their enzyme degradation. Fruits 53: 257-270

18. Tharanathan R N, Reddy GC, Muralikrishna G, Susheelamma NS (1994) Structure of a galactoarabinan-rich pectic polysaccharide of native and fermented blackgram (Phaseolus mungo). Carbohydrate Polymers 23: 121 127.
19. Sakamoto T, Sakai T (1995) Analysis of structure of sugar-beet pectin by enzymatic methods. Phytochem 39: 821-823.

20. Obro J, Harholt J, Scheller HV, Orfila C (2004) Rhamnogalacturonan-I in Solanum tuberosum tubers contains complex arabinogalactan structures. Phytochem 65: 1429-1438.

21. Garna H, Mabon N, Nott K, Wathelet B, Paquot M (2006) Kinetic of the hydrolysis of pectin galacturonic acid chains and quantification by ionic chromatography. Food Chem 96: 477-484.

22. Hwang J, Kokini JL (1992) Contribution of the side branches to rheologica properties of pectins. Carbohydrate Polymers 19: 41-50. 